\title{
LOS GUARDIANES SILENCIOSOS DE LA QUEBRADA DE HUMAHUACA: ETNOBOTÁNICA DEL "CARDÓN" (TRICHOCEREUS ATACAMENSIS, CACTACEAE) ENTRE POBLADORES ORIGINARIOS EN EL DEPARTAMENTO TILCARA, JUJUY, ARGENTINA
}

\author{
MARÍA F. BARBARICH ${ }^{1}$ \& MARÍA E. SUÁREZ ${ }^{1}$
}

\begin{abstract}
Summary: Barbarich, M. F. \& M. E. Suárez. 2018. The silent guardians of the Quebrada de Humahuaca: the ethnobotany of the "cardón" (Trichocereus atacamensis, Cactaceae) among indigenous people of the Department of Tilcara (Jujuy, Argentina). Bonplandia 27(1): 59-80.
\end{abstract}

The "cardón", Trichocereus atacamensis, is an emblematic species in the Quebrada de Humahuaca (Jujuy, Argentina). However, although data can be found scattered throughout the literature, its ethnobotany has never been studied in depth. The aim of the present paper is to conduct a comprehensive ethnobotanical study of $T$. atacamensis in the Department of Tilcara (Jujuy, Argentina), among members of the Kolla people, to shed light on the complex interrelations between this human group and the "cardón". The information collected includes narratives, uses, knowledge of the morphology, qualities, ecological and phenological distribution, details of the role of these cacti in the area and other aspects on the relationship between the plants and the people. Results suggest that the phytosanitary state of both the "cardones" and the study area is of concern, and that the very close links with the "cardón", in accordance with traditional cultural patterns and conceptions, are fiercely maintained despite the socioenvironmental changes. This study also highlights the pressing need to devise strategies to gain a better insight into the phytosanitary state of the "cardones" and their habitat, and thus safeguard local relations and knowledge associated with them.

Key words: Andean region, cacti, ethnobiology, indigenous people, Kolla people.

Resumen: Barbarich, M. F. \& M. E. Suárez. 2018. Los guardianes silenciosos de la Quebrada de Humahuaca: etnobotánica del "cardón" (Trichocereus atacamensis, Cactaceae) entre pobladores originarios en el Departamento Tilcara, Jujuy, Argentina. Bonplandia 27(1): 59-80.

\begin{abstract}
El "cardón", Trichocereus atacamensis es una especie emblemática en la Quebrada de Humahuaca. Si bien hay datos dispersos en la literatura, hasta hoy su etnobotánica no ha sido foco de investigaciones. El objetivo del presente trabajo fue realizar un estudio etnobotánico integral sobre Trichocereus atacamensis en el departamento Tilcara (Jujuy, Argentina), con pobladores kollas, para dar luz sobre las complejas interrelaciones entre este grupo humano y los "cardones". La información reunida incluye narrativas, usos, saberes sobre la morfología, cualidades, distribución ecológica y fenología, detalles del rol de estos cactus en la zona y otros aspectos relacionados a los vínculos de la gente con estas plantas. Los resultados sugieren que el estado fitosanitario de los "cardones" y de la zona de estudio es preocupante. Se concluye que los lazos con el "cardón" son estrechos, acordes a pautas y concepciones culturales
\end{abstract}

\footnotetext{
${ }^{1}$ Universidad de Buenos Aires, Facultad de Ciencias Exactas y Naturales, Departamento de Biodiversidad y Biología Experimental. Buenos Aires, Argentina. CONICET-Universidad de Buenos Aires, Instituto de Micología y BotánicaCONICET (INMIBO). Buenos Aires, Argentina. E-mail: fbarbarich@gmail.com, eugesuarez78@gmail.com
} 
tradicionales, y que se mantienen con fuerza a pesar de los cambios socioambientales acaecidos; además, urge pensar estrategias para conocer mejor la situación sanitaria de los "cardones" y su hábitat y resguardar así los vínculos y saberes vernáculos asociados a ellos.

Palabras clave: Cactus, etnobiología, indígenas, pueblo kolla, región andina.

\section{Introducción}

Las plantas son y han sido siempre fundamentales en la historia de los pueblos, no solo por su aprovechamiento y utilidad práctica, sino por el significado y valores que tienen en el seno de cada cultura. Los cactus no son la excepción, sino por el contrario, tienen una gran multiplicidad de representaciones, funciones y usos para las culturas originarias de América; por ello, han sido foco de múltiples investigaciones que se centraron en su empleo, su papel en prácticas ceremoniales y su valor simbólico desde tiempos prehispánicos a la actualidad, siendo México el país que más ha profundizado en estas temáticas (Diguet et al., 1928; Cárdenas, 1951; Sánchez Mejorada, 1982; Casas, 2002). El "cardón" o "pasacana" (Trichocereus atacamensis (Phil.) Backeb., sin: Echinopsis atacamensis (Phil.) Friedrich \& G.D. Rowley) (Fig. 1A-B) es un cactus columnar de la región andina, cuya distribución se restringe a la provincia biogeográfica de la prepuna, que abarca el noroeste de Argentina, suroeste de Bolivia y norte de Chile (Ortega-Baes \& Godínez-Álvarez, 2006). En la provincia argentina de Jujuy es un elemento característico de la Quebrada de Humahuaca, la cual comprende un corredor estrecho de sentido norte-sur, formado por cadenas montañosas tanto en su flanco oriental como occidental, y atravesando los departamentos Humahuaca, Tilcara y Tumbaya (Fig. 2). El área estuvo tradicionalmente ocupada por una multiplicidad de etnias, que algunas décadas antes de la llegada de los españoles fueron parte del extremo sur (kollasuyu) del imperio incaico (Reboratti, 1998). Desde el siglo XIX, dichas etnias se consolidaron espacial y socialmente como las comunidades que conocemos hoy en día bajo la generalización de kollas (Martínez Sarasola, 1992).

Existen variados antecedentes que proporcionan vasta información sobre el empleo y significados de cactáceas, en especial en lo que refiere a sus usos mágicos, terapéuticos y ceremoniales, en diversas culturas mesoamericanas y andinas desde antiguo hasta hoy (Slotkin, 1956; Towle, 1961; Stewart, 1987; Feldman Gracia, 2011). Para el norte de Argentina y sur de Bolivia se cuenta con datos concretos sobre el uso de cactus como alimento y por su madera como combustible y materia prima para diversos objetos, provenientes en su mayoría de estudios etnográficos, arqueológicos y paleoetnobotánicos; algunos de ellos citan que en restos arqueobotánicos de Argentina donde habitaron comunidades kollas se encontró madera proveniente de cactáceas en techos y puertas de viviendas, usos vigentes hasta la actualidad (von Rosen, 1904; Heyne, 1992; Capparelli \& Raffino, 1997; Hilgert \& Kiesling, 2002). El género Trichocereus se encuentra ampliamente representado en estratos de sitios incas andinos, principalmente mediante semillas y espinas relacionadas con hábitos alimenticios o tecnológicos (Pintar, 2004; Petrucci \& Tarragó, 2015). En particular para Trichocereus atacamensis, existen datos etnobotánicos, biológicos y arquitectónicos, sobre su empleo en el pasado y en la actualidad: se utiliza su madera para construcción, muebles y artesanías, sus frutos con fines alimenticios y, en la práctica del coqueo, para la preparación de la "yicta" (mordiente) para la insalivación del acullico (conjunto de hojas de coca, Erythroxylum coca Lam., que se coloca en la boca, en la parte interior de la mejilla) (Kiesling, 1978; Fernández Distel, 1984; Vignale, 1996; Hilgert, 2000; Cruz, 2008; Halloy, 2008; Tomasi \& Rivet, 2011). Sin embargo, se trata de datos inmersos en trabajos más amplios o enfocados en un uso particular de la especie, y ninguno se dedica a estudiar a la especie en forma integral.

El objetivo del presente trabajo fue realizar un estudio etnobotánico integral sobre 

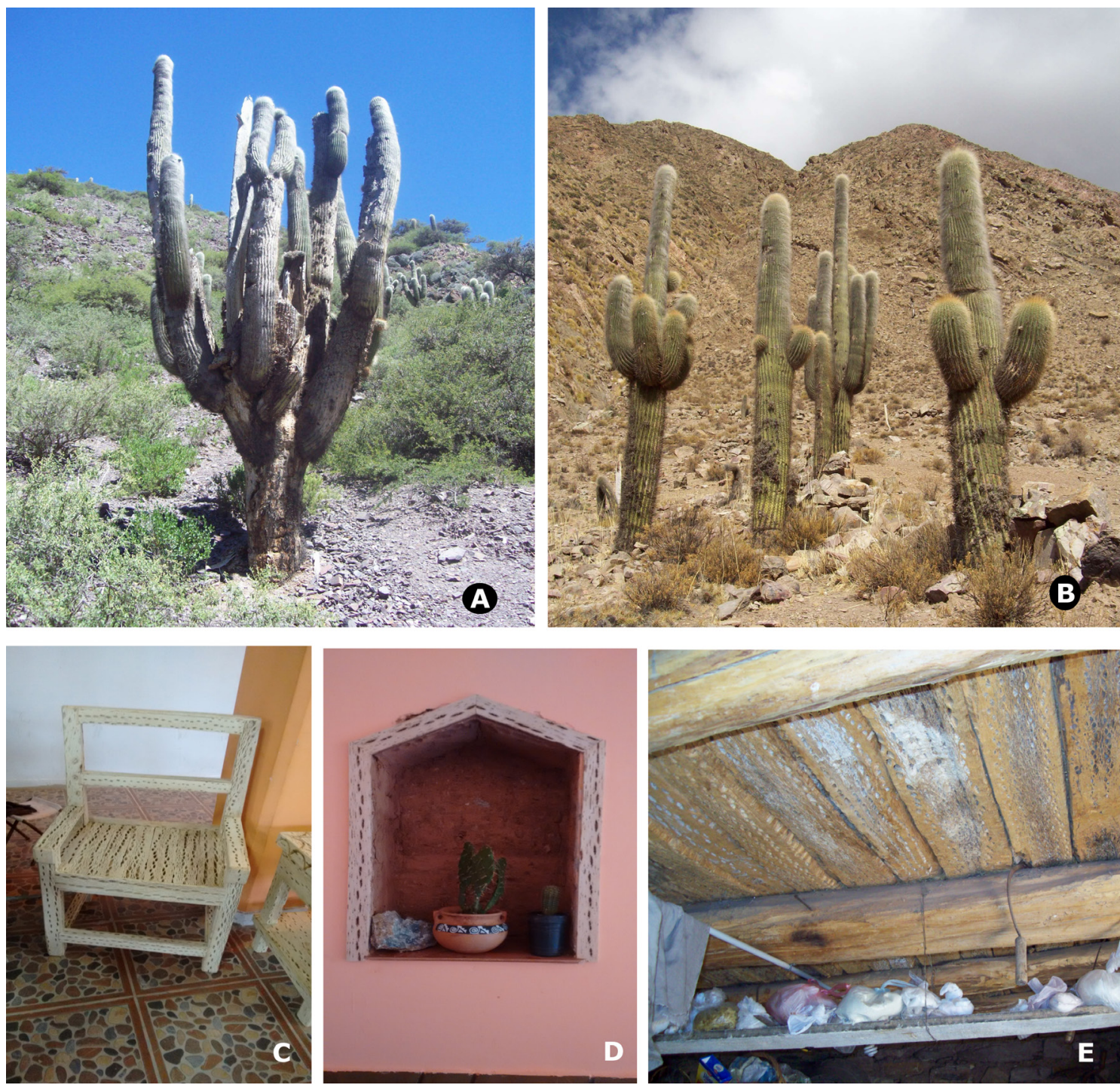

Fig. 1. A: "Cardón" añoso. B: "Cardones" jóvenes. C: Silla hecha con madera de "cardón". D: "Cardón" pequeño ornamental (creciendo en maceta de la derecha). E: Techo de casa hecho de madera de "cardón".

Fig. 1. A: An elder "cardón". B: Young "cardones". C: Chair made with "cardón" wood. D: A small "cardón" used as ornamental (growing in the right pot). E: A home roof made of "cardón" wood.

Trichocereus atacamensis en el departamento Tilcara, Jujuy, Argentina, con personas que se adscriben como pertenecientes o descendientes del pueblo kolla. En este sentido, la propuesta es registrar, compendiar y analizar en forma contextualizada saberes, prácticas, significados, usos y manejo del "cardón", para dar luz sobre las complejas interrelaciones que este grupo humano mantiene con los "cardones" de la Quebrada de Humahuaca.

\section{Materiales y Métodos}

\section{Contexto cultural y ambiental}

La Quebrada de Humahuaca es una región cuya individualización responde no solo a categorías ecológicas y geográficas, sino a una historia de construcción conceptual del territorio que incluye aspectos sociales, culturales y políticos (Solari, 1907; Benedetti 2012). Abarca el sistema de la principal cuenca hidrogeológica 
de la región, asociada al Río Grande, y los fondos de valles fértiles localizados en un conjunto de quebradas tributarias transversales. Fitogeográficamente está incluida en la Provincia Prepuneña del Dominio Chaqueño, con predominancia de las fisonomías de estepa y matorral xerofítico, con vegetación arbustiva baja y esparcida y una flora caracterizada por la marcada abundancia de cactáceas columnares del género Trichocereus (Cabrera, 1971). Este paisaje limita y es de transición hacia el este con los pastizales de altura y con las selvas de Yungas (o nubiselva montana), y hacia el oeste con la meseta elevada del altiplano andino.

La Quebrada de Humahuaca incluye en su territorio a tres de los dieciséis departamentos de la provincia de Jujuy: Tumbaya, Humahuaca y Tilcara, siendo este último donde se concentra el presente estudio (Fig. 2B). Allí se trabajó con personas que se reconocen como pertenecientes o descendientes del pueblo kolla. La gente que se reconoce vinculada al mismo representa el $52,5 \%$ de los pueblos originarios presentes en la provincia de Jujuy (INDEC, 2010), con un origen común quechua o aymara (García Moritán \& Cruz, 2012; Yudi, 2014). El nivel de alfabetismo y de escolarización de la población originaria en la provincia es alrededor del 90\% (INDEC, 2010). En cuanto al idioma, durante la organización colonial las múltiples lenguas locales de la zona fueron desapareciendo, quedando el quechua como lengua nativa (Karasik \& Machaca, 2016). Actualmente el pueblo kolla de Jujuy es mayoritariamente monolingüe en español y algunas pocas personas son bilingües quechua-español. En el léxico cotidiano de todos los pobladores existen numerosas reminiscencias de las lenguas quechua y aymara (De Granda, 1993; López, 2010). En la Quebrada de Humahuaca, particularmente en el Dpto. Tilcara, la población en general (kollas y no kollas) se distribuye de forma heterogénea, con una mayor densidad en los pueblos principales -Tilcara y Maimará son los más importantes- y con un bajo número de habitantes asentados de forma dispersa en zonas rurales o semirurales (Fig. 2B). Los campesinos agricultores-ganaderos producen principalmente para autoconsumo, organizando tradicionalmente su vida cotidiana acorde al calendario agrícola. Desde el siglo XX se profundizó la venta de la mano de obra como fuente de ingreso al grupo familiar, con el consecuente incremento de migraciones y de ocupaciones en actividades no agropecuarias; a eso se suman ingresos provenientes de ayudas sociales gubernamentales, todo lo cual llevó a una creciente incorporación de bienes de consumo de origen industrial (Ros \& Schneider, 2008). A las prácticas tradicionales han sumado en las últimas décadas empleos estatales o privados, vinculados principalmente a actividades relacionadas con el creciente turismo (Bergesio \& Montial, 2008). En el año 2003 la Quebrada de Humahuaca fue declarada Patrimonio Natural y Cultural de la Humanidad por la UNESCO, lo cual trajo consigo cambios en la ocupación del territorio y en las actividades económicas desarrolladas, asociados principalmente a la aparición de un turismo más diverso y cuantioso (Troncoso, 2009). A pesar de ello, aún en las ciudades, se han mantenido de forma complementaria las actividades de agricultura-ganadería de organización familiar, principalmente para autoconsumo. En los modos de desarrollar sus actividades y en diversas prácticas sociales (el culto a la Pachamama, la celebración del carnaval como hito que marca tiempo de cosecha, las ceremonias vinculadas al ganado, entre otros), se evidencia un vínculo fuerte y estrecho con su entorno, acorde a su cosmovisión (Mariscotti, 1966; Karasik \& Machaca, 2016).

\section{Recopilación, procesamiento y análisis de la información}

Este trabajo surge de una investigación más amplia desarrollada en el marco de la tesis de postgrado de la primera autora, dedicada a la etnobotánica de 3 especies del género Trichocereus en la provincia de Jujuy, incluyendo la que compete al presente artículo. En líneas generales, se trabajó siguiendo la metodología clásica de la etnobotánica, combinando trabajo de campo, de laboratorio y de gabinete (Arenas \& Martínez, 2012). La información original y materiales de referencia fueron obtenidos a través de entrevistas abiertas y semiestructuradas, recorridos por el entorno y observación participante, durante seis trabajos de campo realizados en las localidades de Tilcara, Juella, Maimará y Huichaira y parajes 

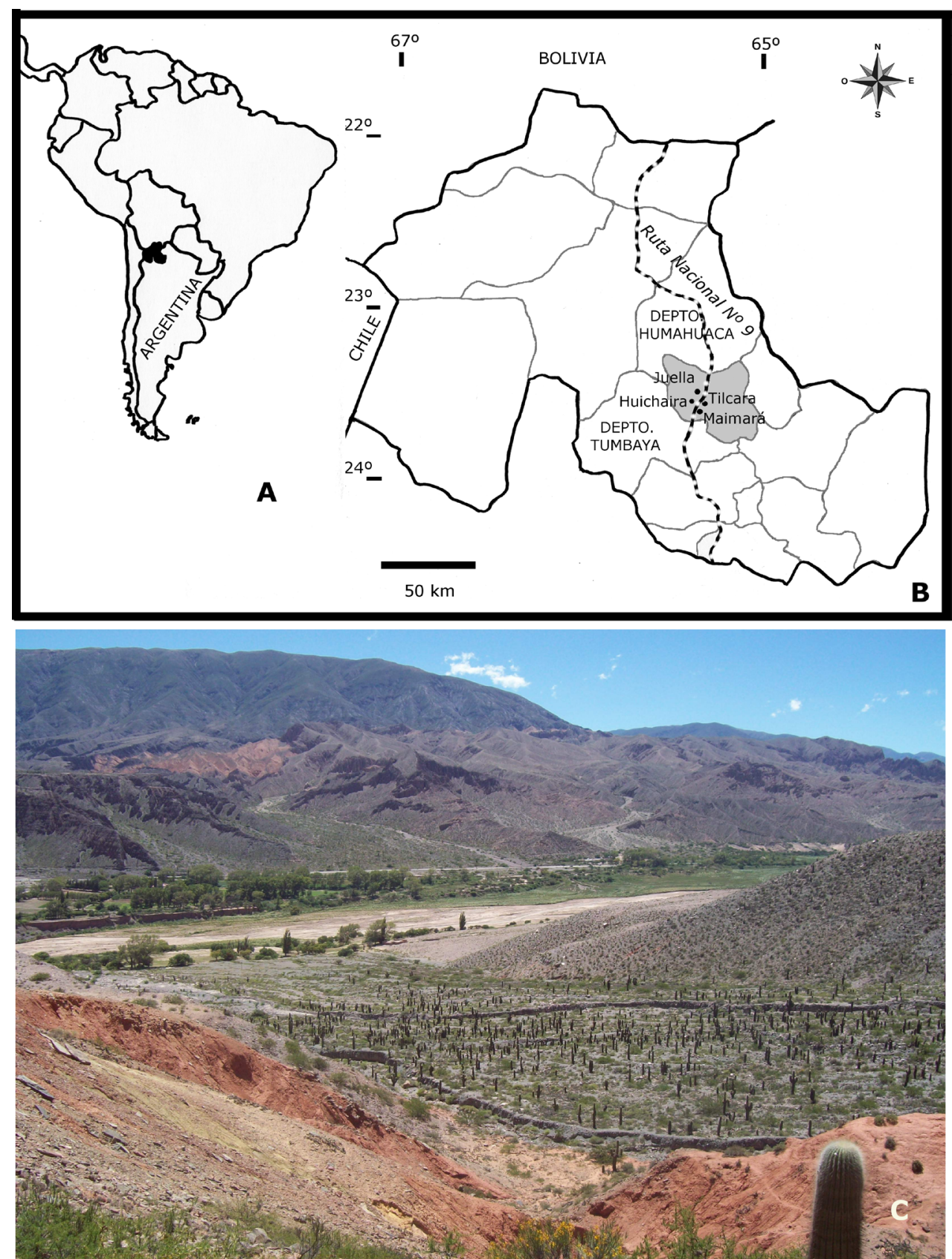

Fig. 2. Zona de estudio. A: Mapa de América del Sur, indicando la localización de la provincia de Jujuy en Argentina. B: Mapa de Jujuy, indicando la localización de los departamentos (el departamento Tilcara está sombreado en gris), pueblos y ciudades mencionadas. C: Paisaje típico de la Quebrada de Humahuaca.

Fig. 2. Study area. A: Map of South America, indicating the location of the province of Jujuy within Argentina. B: Map of Jujuy, indicating the location of the departments (Tilcara department is shaded in grey), villages and towns mentioned in the study. C: Typical landscape of the Quebrada de Humahuaca.

de los alrededores de las mismas (Fig. 2B). Las campañas, de un mes de duración promedio cada una, se desarrollaron en distintas estaciones del año entre los años 2015 y 2018. Se trabajó con un total de 60 colaboradores adultos, 41 varones y 19 mujeres, de 30-85 años de 
edad. De niños, todos fueron criados en áreas rurales y han completado por lo menos el nivel de escolarización primario. En todos los casos, siguiendo las recomendaciones del código de ética de la Sociedad Internacional de Etnobiología (ISE, 2006), se obtuvo el consentimiento informado previo en forma oral de cada persona con la que se trabajó y de las autoridades locales. Para la recolección del material biológico, se tramitaron y obtuvieron los permisos provinciales correspondientes (Resoluciones del Ministerio de Ambiente de la Provincia de Jujuy No106/2015-DPB, No044/2016-S-B y No091/2017-S-B). Tras ser identificados, los ejemplares se depositaron en el Herbario del Museo de Ciencias Naturales "Bernardino Rivadavia" (BA), Buenos Aires, Argentina. La identificación de las especies siguió el criterio planteado por la base de datos Flora del Conosur (Zuloaga et al., 2008), de actualización permanente. Los nombres de aquellas especies que no se encuentran en dicha base de datos, siguen la nomenclatura de The Plant List (2013).

Los datos fueron analizados con un enfoque holístico e interpretativo, evaluando en forma conjunta y contrastando el contenido de entrevistas, los datos de observación participante y la información de fuentes bibliográficas (Arenas \& Martínez, 2012; Wahyuni, 2012).

\section{Resultados}

\section{Nombres e identificación}

Los colaboradores utilizan la voz "cardón" (plural: "cardones") con distintos sentidos. La palabra "cardón" hace alusión, en la zona de estudio, a las tres especies con porte erguido (o candelabriforme) y que tienen mayor tamaño, presentes en la provincia: Trichocereus atacamensis, Trichocereus tarijensis (Vaupel) Werderm. y Trichocereus terschekii (Parm. ex Pfeiff.) Britton \& Rose. Entre estas tres, la voz "cardón" se asigna además como nombre propio de la primera, foco del presente estudio. Las dos especies restantes reciben otros nombres: T. tarijensis se llama "cardón poco", "poco" o "poco-poco", y T. terschekii se denomina "cardón de los valles" o "pocoto". Por otro lado, los entrevistados eventualmente llaman "cardoncitos" (i.e. "cardón" + -citos, sufijo diminutivo plural) a otras especies con hábito o morfología similares y de menor tamaño que dichas especies, que aparte pueden tener o no un nombre propio ( $\mathrm{p}$. ej. Trichocereus schickendantzii (F.A.C. Weber) Britton \& Rose, u Oreocereus trollii (Kupper) Backeb.). Los pobladores distinguen claramente los 3 "cardones" de la zona de estudio entre sí ( $T$. atacamensis, T. terschekii y T. tarijensis) en base a un conjunto de características: T. atacamensis se identifica y diferencia principalmente por su porte erguido y mayor al de los demás, con un tronco principal, ramas primarias y algunas secundarias que crecen "pegadas" o "cerquita" del tronco principal, y por el color blanco de la flor; T. tarijensis tiene un porte menor y flor roja; T. terschekii crece en sitios diferentes (al pie de Yungas y en la transición al Chaco serrano), tiene más ramificaciones y sus espinas sirven para diferenciarlos. Las espinas son una parte clave para distinguir especies, explican, siendo las de T. atacamensis más gruesas y largas. Refieren y conocen la existencia de dichas especies en otras provincias del noroeste argentino (NOA), lo cual explican en términos ecológicos de continuidad de características ambientales; más aún, sostienen que a distintas altitudes o condiciones climáticas, los ejemplares de una y otra provincia presentan algunas diferencias, p. ej. "los cardones de Salta son más brazudos" (i.e. tienen más ramas laterales). A nivel local, los pobladores reconocen variaciones entre individuos de la misma especie, las cuales asocian a diferencias del suelo, a los vientos o a las posibilidades de la planta para crecer, pero no los nombran de modo distintivo.

El“cardón" propiamentedicho, T.atacamensis, también puede ser llamado "pasacana", aunque esta voz alude primariamente a su fruto. Los informantes explican que es un nombre válido para el "cardón", pero la mayoría solo lo utiliza para nombrar al fruto y lo usan como nombre del cactus solo cuando precisan diferenciarlo de otros "cardones". Según los interlocutores, el origen del término "pasacana" aplicado al fruto (y por extensión al cactus) se explica porque una de las formas de consumirlo es "seco como una pasa" (el término "pasa", en Argentina y a nivel regional, se utiliza como sustantivo para hacer alusión a frutos carnosos desecados, como la 
"pasa de uva" o "uva pasa", Vitis vinifera L., la "ciruela pasa", Prunus domestica L., o el "higo pasa", Ficus carica L.), que es el estado en el que el fruto del "cardón" se encuentra al final de su madurez (seco y arrugado), y está recubierto de vellosidades que asemejan a pelos blancos o canas (Fig. 3C-D). Otro nombre que suele darse a . atacamensis es "cardón grande", que los
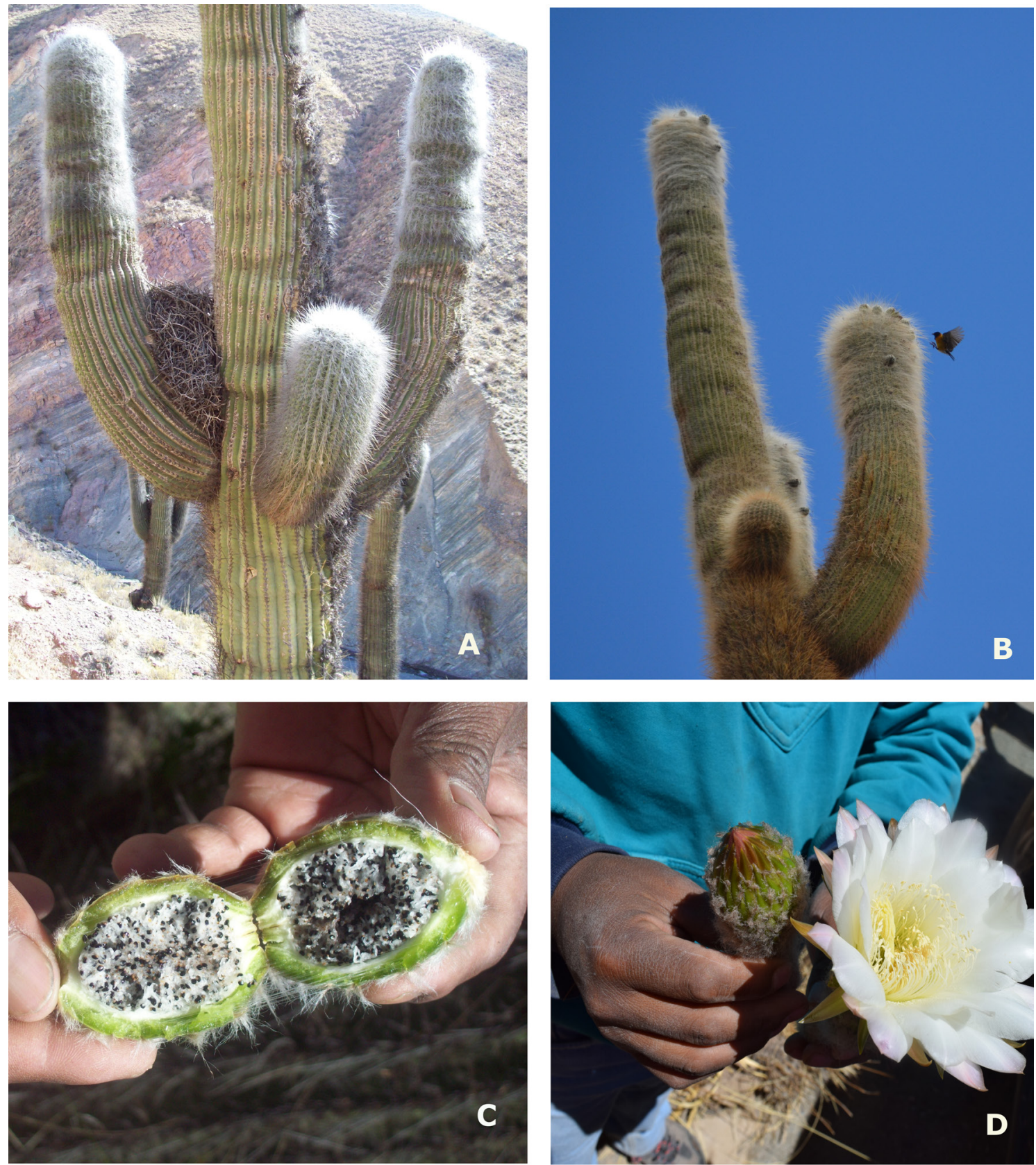

Fig. 3. A: Nido de ave entre los "brazos" del "cardón". B: Ave (Phrygilus atriceps) visitando un "cardón". C: Fruto abierto del "cardón". D: Fruto y flor del "cardón".

Fig. 3. A: Bird nest in the "arms" of the "cardón". B: Bird (Phrygilus atriceps) visiting a "cardón". C: Open fruit of the "cardón". D: Fruit and flower of the "cardón". 
pobladores explican por tratarse del "cardón" más grande y de mayor envergadura en la zona. Una vez más, este término se utiliza, de todas formas, para resaltar a esta especie de otras especies del género. Teniendo en cuenta lo antedicho y para evitar confusiones, de aquí en adelante, al hablar de "cardón" o "cardones", nos referimos a la especie foco de nuestro estudio, T. atacamensis, salvo que se explicite lo contrario.

Ciclo de vida, morfología y cualidades del "cardón"

De acuerdo al relato de muchos pobladores mayores a 50 años (un 60\% del total), los "cardones" "siempre han estado": los de gran tamaño preexisten a la vida de las personas, o si los ven nacer, los "cardones" las sobreviven. No hay claridad ni explicaciones exactas respecto a la edad, pero sostienen que llegan a ser muy viejos (Fig. 1A) y que crecen muy lento (1-3 cm por año), y por ello concluyen que los más altos que hay en la quebrada serían ejemplares centenarios, de al menos 300-500 años. Existen algunos "cardones" que son reconocidos de forma individual por tratarse de los más antiguos. Estos "cardones" adquieren así una identidad particular, la gente conoce su localización exacta y es frecuente que los entrevistados los identifiquen y los señalen durante los recorridos por el entorno; un caso particular es el "Abuelo", sito en el paraje Hornaditas, en el departamento de Humahuaca.

En lo que respecta a la morfología, en la Tabla 1 se detallan los nombres, descripciones y cualidades destacadas de las partes del "cardón" desde la perspectiva vernácula. A ello hay que agregar que la gente remarca permanentemente la similitud morfológica de los "cardones" con la de una persona; es común, por ejemplo, que por las tardes, con el reflejo del sol poniéndose, se enfatice que los "cardones" parecen un "ejército en los cerros" (Figs. 2C, 4). Además de la apariencia externa, la gente describe a los "cardones" como "porfiados", "picaros", "traviesos", "agresivos", "contreros" (que llevan la contraria en sus actos) o "serios", y remarcan que de acuerdo con su voluntad a veces deciden pinchar a una persona, o crecer o no en un sitio específico.
De acuerdo con los entrevistados, existe un ciclo anual que se repite con variaciones menores en función de si son años más fríos o cálidos, o de si las altas temperaturas de verano empiezan tardíamente. Describen que hacia la primavera, cuando "empiezan los calores" o "el sol pega más fuerte", aparecen los botones florales, que se abren alrededor de noviembre, momento en el cual son visitados por un alto número de insectos que "ayudan a que después haya frutos" (polinizadores). Destacan que el número de flores por "cardón" es elevado y que la antesis dura poco tiempo y no siempre ocurre en simultáneo. Hacia mitad del verano ya son evidentes los frutos, portadores de un gran número de semillas (Fig. 3C), de las cuales, afirman, sólo unas pocas llegarán a germinar y ser "cardones" nuevos. Los ejemplares muy jóvenes no dan flores. La gente no puede precisar el momento en el cual "los cardones ya están maduros entonces ya florecen", pero sí remarcan que una vez que comienzan a dar flores, nunca dejan de hacerlo, aunque hay temporadas que pueden dar más o menos flores. Es así que solo al secarse se acaba la floración, por lo cual se dice que " $a$ veces son engañosos, un verano están de lo más bien, llenos de flores, $y$ al siguiente secos".

En general la gente reconoce dos clases de muerte de los "cardones": por causa "natural" o antrópica ("por efecto del hombre"). En el primer caso, reconocen como la más frecuente a la edad del "cardón". Cuando "mueren de viejos", de un momento a otro empiezan a secarse y "mueren en pie", quedando la madera disponible para su uso. Ciertos factores ambientales, como las heladas o rayos pueden llevar a los "cardones" a la muerte. Por otro lado, todos los informantes coinciden en que desde hace alrededor de 20 años, una nueva causa aparentemente de origen "natural" ha aparecido: la pudrición, que se ha expandido de manera abrumadora y se observa en varias poblaciones de "cardones" a lo largo de la Quebrada de Humahuaca. En este caso los "cardones" "se pudren desde adentro" y, en lugar de morir en pie, caen al suelo, donde la pudrición avanza y se desintegran por completo. Se destaca que el olor es pestilente, y que los líquidos producidos por la descomposición del "cardón" caen y se esparcen por el suelo y tienen una gran cantidad de gusanos, dejando una 
M. F. Barbarich \& M. E. Suárez, Etnobotánica del “cardón” (Trichocereus atacamensis) en Dpto. Tilcara, Jujuy, Argentina

Tabla 1. Nombres vernáculos para las distintas partes del "cardón”, sus correspondencias para la botánica académica, descripciones de los entrevistados y observaciones.

Table 1. Vernacular names for the various parts of the "cardón", their correlations for academic botany, details provided by the interviewees and observations.

\begin{tabular}{|c|c|c|}
\hline Nombre vernáculo & $\begin{array}{l}\text { Correspondencia } \\
\text { botánica }\end{array}$ & Detalles y observaciones \\
\hline “Cuerpo" & Tallo & Tronco, tallo principal. \\
\hline "Brazos", "Guaguas" & Ramificaciones & $\begin{array}{l}\text { Sobre todo a las ramas pequeñas se las llama } \\
\text { "guaguas" }\end{array}$ \\
\hline "Pulpa", "Carne" & Parénquima cortical & $\begin{array}{l}\text { Parte interior blanda. A veces los entrevistados } \\
\text { explican que existe una parte de la pulpa "más" blanda } \\
\text { que el resto. Destacan que la pulpa "es casi todo } \\
\text { agua" (parénquima acuífero), y adjudican a ello la } \\
\text { vulnerabilidad del cardón ante heladas. No mencionan } \\
\text { un nombre específico ni un tejido particular de } \\
\text { almacenamiento de agua. }\end{array}$ \\
\hline "Madera" & Xilema secundario & $\begin{array}{l}\text { Explican que la madera se forma cuando una } \\
\text { porción de la "carne", inicialmente no tan dura, se } \\
\text { va engrosando y endureciendo, y que se termina } \\
\text { de constituir al secarse. La dureza de la madera se } \\
\text { relaciona con la edad y tamaño del individuo. }\end{array}$ \\
\hline "Corazón" & Parénquima medular & $\begin{array}{l}\text { Es el de color más claro. No se especifica si aquí (el } \\
\text { parénquima acuífero) contiene más o menos agua que } \\
\text { el cortical. }\end{array}$ \\
\hline $\begin{array}{l}\text { "Corteza", "cáscara", } \\
\text { "cáscara dura", "piel } \\
\text { dura" }\end{array}$ & $\begin{array}{l}\text { Epidermis con cutícula } \\
+ \text { Clorénquima }\end{array}$ & “Todo lo que envuelve al cardón", "la piel dura”. \\
\hline "Espinas" & Espinas & $\begin{array}{l}\text { Se suele observar su grosor, dado que éste denota } \\
\text { la edad aproximada del individuo, y junto con otros } \\
\text { caracteres les permite, además, diferenciar entre } \\
\text { especies del género. }\end{array}$ \\
\hline "Raíces" & Raíces & $\begin{array}{l}\text { Destacan que no son muy profundas y que se "meten } \\
\text { entre las piedras para agarrarse". }\end{array}$ \\
\hline "Flor" & Flor & $\begin{array}{l}\text { Siempre presentan color blanco y no tienen perfume, } \\
\text { lo cual es una característica usada para diferenciarlos } \\
\text { de otras especies. De acuerdo al nivel de } \\
\text { escolarización, algunos entrevistados recuerdan que } \\
\text { hay nombres para las distintas partes, pero los han } \\
\text { olvidado o no los utilizan, dado que no los necesitan } \\
\text { para su vida cotidiana, según explican. }\end{array}$ \\
\hline "Pie" (de la flor) & Pericarpelo & Cumple la función de unir la flor al cuerpo. \\
\hline "Pétalos" & $\begin{array}{l}\text { Piezas del perianto } \\
\text { petaloides }\end{array}$ & Son siempre blancos o amarillentos. \\
\hline "Fruto" & $\begin{array}{l}\text { Fruto (baya de ovario } \\
\text { ínfero, pseudobaya) }\end{array}$ & $\begin{array}{l}\text { Los entrevistados explican que se origina de la } \\
\text { flor y sigue unido al cuerpo por el mismo pie. Una } \\
\text { vez maduros, los frutos se "desprenden" desde el } \\
\text { pie y caen al piso, muchas veces reventándose y } \\
\text { exponiendo las semillas. }\end{array}$ \\
\hline "Cáscara" (del fruto) & Pericarpelo & $\begin{array}{l}\text { Es dura y gruesa, hacia la madurez "se abre". Cuando } \\
\text { el fruto está inmaduro es de color verde y cuando } \\
\text { maduro, verde-amarillento. }\end{array}$ \\
\hline "Pulpa" (del fruto) & $\begin{array}{l}\text { Pulpa (mesocarpio } \\
+ \text { funículos) con } \\
\text { semillas }\end{array}$ & Es de color blanco. \\
\hline
\end{tabular}




\begin{tabular}{|ccl|}
\hline $\begin{array}{c}\text { Nombre vernáculo } \\
\begin{array}{c}\text { "Janas", "espinitas" (del } \\
\text { fruto) }\end{array}\end{array}$ & $\begin{array}{c}\text { Correspondencia } \\
\text { botánica } \\
\text { Gloquidios }\end{array}$ & $\begin{array}{l}\text { A diferencia de otros cactus, el fruto "no lastima ni } \\
\text { pincha". }\end{array}$ \\
\hline "Pelos" (del fruto) & Pelos & $\begin{array}{l}\text { Está completamente cubierto, se relaciona con la } \\
\text { denominación del fruto. }\end{array}$ \\
\hline & Semillas & $\begin{array}{l}\text { Según los entrevistados, "hay miles por fruto" y se } \\
\text { dispersan principalmente por viento o por pájaros que } \\
\text { las comen. Son de color negro. }\end{array}$ \\
\hline
\end{tabular}

mancha negra persistente y afectando a otras plantas que entran en contacto con ellos. La pudrición de los "cardones" se concibe como una situación ambigua, de origen dudoso. Los entrevistados creen que se trata de una causa "natural", pero relacionada con efectos antrópicos, como la contaminación del aire o la cercanía a basurales, i.e. correspondería a una categoría intermedia, ya que el efecto directo lo produce un agente "natural", pero a su vez éste tiene origen antrópico. Respecto a la muerte causada directamente por las acciones del hombre, el motivo principal expresado es el corte intencional y selectivo de "cardones". Esta acción siempre ha existido y se mantiene hasta hoy, pero según explican, a diferencia de lo que ocurría antaño, actualmente se realiza en forma desmedida, principalmente por la explotación de la madera para fines turísticos o comerciales acorde al sistema capitalista hegemónico (véase siguiente sección). La práctica tradicional de seleccionar y cortar "cardones" se considera en muchos casos un modo de "limpiar los cardonales", lo cual, según explican, trae consecuencias benéficas al remover ejemplares adultos y "dar lugar a los nuevos", como así también aquellos que lucen enfermos. Al respecto, relatan que "cuando usábamos más madera andábamos siempre junando (observando) cómo estaba el cardonal'.

\section{Usos prácticos del "cardón"}

Se registró la utilidad de los "cardones" con diversos fines, los cuales fueron clasificados $\mathrm{y}$ ordenados ad-hoc en categorías etic para su análisis y sistematización. En la Tabla 2 se compendian dichos usos y se brindan detalles de los mismos.

\section{Sobre los orígenes del "cardón"}

Existe un relato vigente en la región, con múltiples variantes en sitios vecinos y de acuerdo al interlocutor, que da cuenta que los "cardones" tendrían origen humano. En términos generales, la historia cuenta que una princesa humahuaqueña (el término princesa lo emplean los entrevistados) y un cacique del Tukma (Tucumán) se enamoraron, pero que ese amor no era aceptado por el grupo social de la princesa. En una ocasión, el cacique se encontraba en la Quebrada de Humahuaca junto a su ejército, con la intención de llegar hasta Humahuaca a buscar a la princesa; fue entonces que una maldición los convirtió en palo. De esos palos brotaron los "cardones", que pasaron a ser los guardianes de los sitios sagrados, y cuyas flores representan la belleza del amor entre ellos. Las múltiples variantes de la narrativa explican o amplían distintas partes de la misma. Así, algunos sostienen que la maldición provino del odio que la tribu de la princesa tenía hacia el cacique tucumano. Otros afirman que se trata de un castigo de la Pachamama por un romance indebido. También existen quienes creen que el hechizo no fue una maldición, sino que permitió, en un contexto hostil, la perpetuación del amor mediante la conversión de los protagonistas en plantas longevas. A la par de las variantes del origen de la maldición, existen versiones sobre cómo las personas se convirtieron en "cardones". Algunas recopilaciones afirman que la transformación fue directa, otras que primero hubo un pasaje por palos. Una tercera variante cuenta que durante la conversión el príncipe abrazaba a la princesa, por lo que ella se convirtió en flor y él en el cuerpo del "cardón", y que sus hijos fueron "cardones" nuevos que aún hoy siguen 
M. F. Barbarich \& M. E. Suárez, Etnobotánica del “cardón” (Trichocereus atacamensis) en Dpto. Tilcara, Jujuy, Argentina

Tabla 2. Categorías de uso, partes empleadas y usos específicos del "cardón”.

Table 2. Categories of use, parts employed and specific uses of the "cardón".

\begin{tabular}{|c|c|c|}
\hline Categoría & $\begin{array}{c}\text { Partes } \\
\text { utilizadas }\end{array}$ & Usos específicos \\
\hline Combustible & Madera & $\begin{array}{l}\text { Leña en casos de escasez de otros combustibles, i.e. leña de emergencia. } \\
\text { No es buscada ni preferida, ya que se consume muy rápido, humea } \\
\text { mucho, forma poca brasa y es "cenizuda" (forma mucha ceniza). }\end{array}$ \\
\hline Alimentación & $\begin{array}{l}\text { Frutos } \\
\text { Tejidos } \\
\text { vegetativos }\end{array}$ & $\begin{array}{l}\text { Son consumidos por su rol nutritivo. Son muy valorados por los pastores en el } \\
\text { campo por tratarse de un alimento de aporte calórico y nutricional, quienes los } \\
\text { consumen al paso. Se comen pelándolos (Fig. } 3 \mathrm{C} \text { ). Algunos también elaboran } \\
\text { con ellos jaleas o mermeladas. Seco, molido y calcinado se emplea como } \\
\text { componente de la "yicta", usado como mordiente para la insalivación (práctica } \\
\text { del coqueo) del acullico con las hojas de coca (Erythroxylum coca). } \\
\text { Se pueden consumir para saciar el hambre e hidratarse. }\end{array}$ \\
\hline Hidrorreservante & Mucílago & $\begin{array}{l}\text { En condiciones de extrema sequía o falta de disponibilidad de agua actúa } \\
\text { como un elemento hidratante. De vital importancia para los pastores que } \\
\text { pasan largas temporadas en los cerros con el ganado. Para su consumo } \\
\text { puede realizarse una incisión menor y recoger el mucílago que emana de } \\
\text { la planta o también se pueden cortar los tallos/ramas jóvenes, verdes, y } \\
\text { apretarlos para extraer y beber el mucílago. }\end{array}$ \\
\hline Medicinal & Mucílago & Rehidratante, analgésico y protector gástrico. \\
\hline & Fruto & Calma la "fiebre estomacal" (acidez gástrica). \\
\hline Veterinaria & Fruto & $\begin{array}{l}\text { Suplemento alimenticio nutritivo y energético. Se administra en el campo o en } \\
\text { el corral a animales que han parido recientemente o que se encuentran con } \\
\text { bajo peso. }\end{array}$ \\
\hline Tecnología & $\begin{array}{l}\text { Planta } \\
\text { entera }\end{array}$ & $\begin{array}{l}\text { Se utilizaron antiguamente como estrategia militar para simular ejércitos } \\
\text { de mayor número de soldados. En zonas rurales actualmente se lo utiliza } \\
\text { ocasionalmente como espantapájaros, vistiéndolos con diversas prendas y } \\
\text { lanas. } \\
\text { De gran valor para elaborar diversos objetos de la cultura material (p.ej. } \\
\text { bancos, sillas, mesas, adornos del hogar) (Fig. } 1 \text { C). } \\
\text { Para construcción. Puede utilizarse con o sin procesamiento, último caso } \\
\text { implica la elaboración de tablas por parte de habitantes que poseen } \\
\text { conocimientos específicos, que constituye todo un oficio y una especialización } \\
\text { en la carpintería. Se utilizan en el ámbito doméstico para elaborar vigas, } \\
\text { techos, puertas, mobiliario, cercos para corrales, aberturas y postes (Fig. } \\
1 \text { E). Los troncos más grandes pueden ocuparse enteros para vigas/ } \\
\text { columnas en la construcción, o pueden cortarse en porciones más pequeñas, } \\
\text { cepillarse y lijarse y de ese modo obtener tablas similares para cielorrasos. La } \\
\text { elaboración de mobiliario demanda un trabajo más fino para obtener tablas de } \\
\text { dimensiones y grosores muy similares y en muchos casos un espesor menor. } \\
\text { Todos estos conocimientos y el trabajo en madera en general corresponden } \\
\text { al ámbito masculino y se heredan generación en generación o se transmiten } \\
\text { entre personas cercanas de la comunidad. Es frecuente que en ámbitos } \\
\text { rurales los padres preparen tablas de "cardón" para sus hijos cuando estos } \\
\text { inician su vida independiente. } \\
\text { Se utiliza como materia prima de artesanías para la venta (p.ej. aros, } \\
\text { bandejas, marcos para fotos, lámparas), gran parte de las cuales está } \\
\text { destinada a turistas. Desde hace unas décadas, ha cobrado gran relevancia } \\
\text { la utilización de la madera procesada con fines decorativos, sobre todo en } \\
\text { emprendimientos destinados al turismo. La presencia de "agujeritos" es típica } \\
\text { en la madera obtenida de los "cardones", y es un rasgo que otorga distinción y } \\
\text { finura a la madera respecto a otras (Fig. } 1 \text { C, E). }\end{array}$ \\
\hline
\end{tabular}




\begin{tabular}{|c|c|c|}
\hline Categoría & $\begin{array}{l}\text { Partes } \\
\text { utilizadas }\end{array}$ & Usos específicos \\
\hline Tecnología & Espinas & $\begin{array}{l}\text { Como agujas para tejer. Refieren que es un uso antiguo y que algunas } \\
\text { personas aún conservan la técnica para hacer "ojos" a las agujas. } \\
\text { Con ellas se elaboran peines para cardar la lana, uniendo con tientos de cuero } \\
\text { o con lanas una serie de espinas de forma paralela. } \\
\text { Para "tiparse" (del quechua "tipay"= clavar, hincar, prender) las prendas, es } \\
\text { decir, a modo de prendedores o broches para cerrar un poncho. }\end{array}$ \\
\hline Juegos infantiles & $\begin{array}{l}\text { Planta } \\
\text { entera }\end{array}$ & $\begin{array}{l}\text { Grupales: rondas (juego del corro) alrededor de un "cardón" o a la } \\
\text { escondida, camuflándose en los cardonales durante la tarde-noche } \\
\text { cuando ya no se distinguen bien las siluetas. } \\
\text { Individuales: compañía cuando los niños pequeños hacen sus primeras } \\
\text { salidas con los rebaños: "cuando tenía mucho miedo mi mamá me decía } \\
\text { que rezara, yo rezaba mucho y enseguida me daba cuenta que estaba } \\
\text { acompañado por los cardones, que no estaba solo. Muchas veces me he } \\
\text { asustado tanto, y así nomás cuando los veía, se me iba". }\end{array}$ \\
\hline Ornamental & $\begin{array}{l}\text { Planta } \\
\text { entera }\end{array}$ & $\begin{array}{l}\text { Implica el transplante de ejemplares adultos o el mantenimiento de } \\
\text { cardones preexistentes con fines ornamentales (Fig. } 1 \mathrm{D} \text { ). En zonas } \\
\text { urbanas, se eligen canteros, plazas o sitios vistosos. Un uso menos } \\
\text { referido es el de cercos vivos, para lo cual son elementos sumamente } \\
\text { útiles, por su gran porte y sus espinas. } \\
\text { Refieren los entrevistados que en la última década hay cardones } \\
\text { disponibles para la venta al turismo en distintas partes del departamento. }\end{array}$ \\
\hline
\end{tabular}

poblando la quebrada. Por último, se registró una versión en la cual el cacique no existe en la historia, y que la princesa humahuaqueña y su gente, al verse amenazados por un ejército conquistador, huyeron de sus tierras y entonces la Pachamama les ofreció protección convirtiéndolos en "cardones". La princesa, una vez por año, emerge en forma de bella flor para ver el mundo.

\section{Los guardianes de la quebrada y de los sitios sagrados}

En los relatos de los pobladores los "cardones" tienen un rol emblemático, definiéndolos como protectores, vigilantes o soldados que cuidan la quebrada desde tiempos inmemoriales hasta hoy. Se destaca su rol protector en sitios que revisten cierta sacralidad, como los "antigales" (Fig. 4). Los "antigales" son asentamientos específicos donde vivieron los antepasados, que hoy en día constituyen sitios arqueológicos y son muy significativos para los actuales descendientes. El papel protagónico como guardián de la región no solo se encuentra en relatos míticos o en el cuidado de sitios sagrados en el presente, sino que los pobladores locales cuentan con orgullo que son los "cardones" quienes definieron el resultado de las batallas por la independencia de Argentina a principios del siglo XIX, ya que el ejército los empleó para simular, por sus características morfológicas, un número mayor de soldados "disfrazándolos" de personas.

\section{Distribución ecológica y relación con otras plantas y animales}

Todos los entrevistados coinciden en que si bien pueden encontrarse "cardones" en otras provincias, son típicos y están presentes en cantidad en este sector de la Quebrada de Humahuaca en particular. Su gran abundancia en esta parte de su área de distribución se explica, según nuestros interlocutores, también por este motivo: están en su ambiente y son ellos quienes -por sobre muchos otros elementos naturales- dan características particulares a la quebrada, tanto estéticas como ambientales o simbólicas. En general, los colaboradores sostienen que la quebrada sin "cardones" es inconcebible.

La distribución del "cardón" por la quebrada es heterogénea: hay zonas que presentan una gran abundancia y otras con una densidad muy baja y ejemplares aislados. Las primeras 

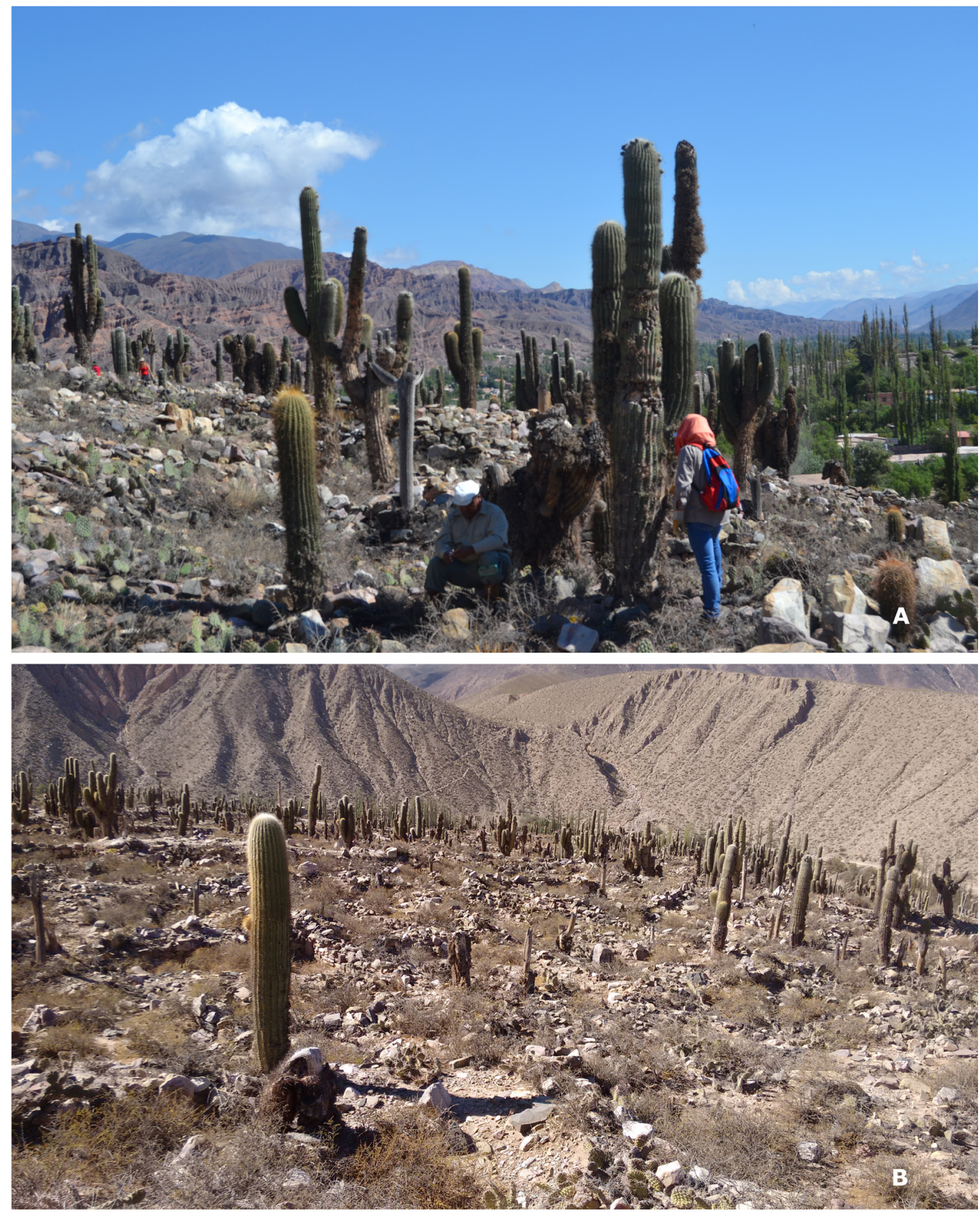

Fig. 4. "Antigales". A: Daños que ocasiona la polilla Cactoblastis bucyrus al "cardón”. B: Se aprecia la abundancia de "guardianes" de estos sitios sagrados.

Fig. 4. "Antigales". A: The damage that the moth Cactoblastis bucyrus produces to the "cardón" can be seen. B: The abundance of "guardians" of these sacred sites can be appreciated.

son denominadas localmente "cardonales" (plural de "cardonal"). La explicación que los entrevistados dan a la distribución particular de los "cardones" no sólo se vincula a los 
relatos míticos explicitados con antelación $\mathrm{y}$ a su función como protector de los sitios sagrados (véase sección anterior), sino también a factores ecológicos (sitios reparados de vientos, con mejor acceso al agua, etc.) y a la voluntad de los "cardones" de crecer donde están creciendo ("deciden crecer en tal o cual lugar", "eligieron estar allá alto en los cerros", "les gusta más ahi"). También remarcan que tienden a crecer asociados a otras plantas o cobijados bajo rocas. Por lo general, la explicación de la distribución se fundamenta en una complementación de todos esos aspectos. Entre las plantas nodrizas más mencionadas para el cardón se encuentran los "churquis" (Prosopis spp.) y los "airampos" (Opuntia spp.). Las rocas también resguardan las semillas o plántulas en sus etapas tempranas de crecimiento. Desde lejos se ven "cardones" solitarios en sitios bastante descubiertos a lo largo de la quebrada, pero quienes frecuentan los cerros explican que aún allí alguna piedrita, laja u otro cactus que las protege en los momentos de mayor vulnerabilidad.

Así como los "cardones" crecen al resguardo de rocas y otras plantas, éstos a su vez brindan albergue a animales. Existen roedores como el "choschori" (Octodontomys gliroides), que además de aprovechar los espacios entre el tronco y las ramas para fabricar sus madrigueras, se alimentan del fruto y, en épocas de escasez, también consumen el tallo. Las aves suelen anidar entre o sobre las ramas; se destacan el "come sebo" y el "pasacanero" (denominaciones locales para Mimus dorsalis, Phrygilus gayi y $P$. atriceps), las cuales además consumen los frutos (Fig. 3A-B). La gente también ha mencionado al "mirlo" (Turdus chiguanco), la "calandria" (nombre que se refiere a diversas especies del mismo género Mimus dorsalis, M. patagonicus, M. triurus, M. saturninus) y el "buche/pecho colorado" (Pytotoma rutila) como aves que frecuentan los "cardones". Los animales de cría también guardan relación con los "cardones", ya que vacas, cabras y ovejas consumen el tallo y/o el fruto de acuerdo a las épocas del año y según disponibilidad de recursos, tanto por voluntad propia o la gente se los da de comer como suplemento en situaciones especiales (p.ej. después de parir, les llevan frutos para que recuperen energías). Según explican, en época de escasez de alimentos y agua, es común que el ganado menor (caprino y ovino) coma "cardones" pequeños; el ganado vacuno, además, golpea los "cardones" con las astas hasta llegar al interior del tallo y consume las partes blandas de ejemplares de gran tamaño. De todas maneras, la gente no percibe a las vacas como una amenaza para el "cardón", ya que sostienen que solo se alimentan de él cuando falta alimento o agua. La asociación entre las aves y el "cardón" se percibe en forma positiva, ya que suele destacarse que dispersan las semillas y comen insectos que pueden dañar los "cardones". Un ejemplo claro y de importancia local-regional es el ejemplo de la "polilla del cardón" (Cactoblastis bucyrus), insecto cuya larva se alimenta del tejido verde del "cardón". Los entrevistados manifiestan que en las últimas dos décadas ha aumentado su población de manera significativa, y sus efectos sobre el bienestar de los "cardones" son visibles a lo largo de la quebrada (Fig. 4A). Para ellos, el aumento tan significativo de un insecto que "siempre ha estado" se debe, al menos en parte, a la disminución de la cantidad de aves que los consumen por el aumento de la urbanización, la contaminación del aire y/o el uso de agroquímicos en las prácticas agrícolas, que envenena y mata a las aves que frecuentan y se alimentan en las zonas de cultivo. Todo esto se vincula con una función clave del "cardón", de acuerdo a muchos de los entrevistados: el estado sanitario de los "cardones" refleja el estado del ambiente. Explican que si los "cardones" se encuentran en mal estado es porque el ambiente también lo está, y de esta forma la situación actual es motivo suficiente para preocuparse por el ecosistema en general en ciertos sitios de la quebrada.

\section{Discusión}

Los resultados indican que el "cardón", Trichocereus atacamensis, es un elemento emblemático en la Quebrada de Humahuaca, de gran significancia para los pobladores originarios que conviven con él desde antiguo. Esta afirmación se sostiene por el conjunto de datos que surgieron de la investigación. En primer lugar, si bien los entrevistados aplican la 
voz "cardón” a 3 especies de Trichocereus de la zona de estudio, el "cardón" por antonomasia es T. atacamensis. La diversidad e importancia de los usos prácticos que tiene la especie (Tabla 2) en la vida cotidiana de la gente también indica su relevancia local. Además de su funcionalidad práctica, existen diferentes usos emblemáticos de la madera de "cardón" en el relato de los pobladores: las capillas más destacadas en la región son aquellas que están "todas hechas en cardón" (refiriéndose al techo principalmente) como el caso de la de Maimará. También se menciona con frecuencia el Cristo de la Virgen de Punta Corral (departamento Tumbaya, Jujuy) cuya cruz de gran envergadura esta tallada sobre una única pieza de "cardón"; en estos casos, además de la función de la madera como soporte de una figura o sitio con significado religioso, se atribuye una mayor relevancia a la pieza por estar hecha del material mencionado, es decir, el valor simbólico del "cardón" se sinergiza con el significado católico del ícono, haciendo que esa pieza sea aún más valorada y se la destaque en el relato cotidiano. Por otro lado, las coplas y otros cantos populares están repletas de referencias al "cardón", lo cual indica su importancia en la zona (Carrizo, 1989). Su rol como protectores de sitios sagrados, que no sólo aparece en el discurso local en relatos históricos sino en las narrativas míticas registradas, es también evidencia de lo antedicho. En línea con ello, en general los "cardones" que se destacan en los relatos son los de mayor tamaño, que han estado en el lugar por siglos, atestiguando y formando parte activa de sucesos relevantes en la historia local.

De esta forma, los "cardones" no son concebidos como un simple recurso por los entrevistados ni son un elemento más en el entorno, sino que, y en concordancia con ello, el vínculo es profundo, intenso y estrecho. Una primera observación al respecto deviene de las narrativas míticas recopiladas sobre el origen (humano) del "cardón". Estos relatos coinciden en términos generales con otros registrados por otras fuentes. Así, existe una narrativa difundida entre los aymara de Bolivia, recopilada por Minhondo (2011), de la cual podrían derivar las variantes locales. Dicha versión cuenta que Kiwayu y Pasacana eran dos enamorados separados en dos bandos por una pelea de caciques, que ante intentos de fuga infructuosos intentaron pactar con el diablo para ser escondidos, pero el pedido a cambio del favor era excesivo. Entonces Pasacana pidió protección a la Pachamama, quien los convirtió en "cardón", poniendo en su interior a Pasacana con la orden de no salir nunca de allí. Mientras que el "cardón" crece fuerte y espinoso para protegerla, es ella quien cada tanto se asoma a bañarse de sol o de luna (serían las flores), y los hijos de ellos fueron los "cardones" que poblaron los Andes. A diferencia de ésta existe una versión muy difundida en páginas web (cfr. p.ej. https://pueblosoriginarios.com/sur/ andina/diaguita/cardon.html) sobre Amaicha del Valle (Tucumán, Argentina) que da cuenta que los "cardones" aparecieron en tiempo de la conquista, momento en el cual los pueblos originarios debían organizarse mediante mensajeros para mantener la comunicación. Un primer mensaje indicó buscar los mejores lugares entre los cerros para ver la llegada del enemigo, pero el siguiente mensaje, que ordenaba atacar, no llegó pues los mensajeros fueron capturados. Fue entonces que la Madre Tierra intervino, durmiendo a los hombres y mujeres e integrándolos a ella, otorgándoles raíces y cubriendo sus cuerpos con espinas para que no fueran molestados. Otra versión (Villafuerte, 1986) que se registra para el NOA cuenta que la joven era la hija de un cacique y el joven un humilde integrante de la tribu. El padre de ella se oponía a la relación y por ello los jóvenes decidieron fugarse, ante lo cual el cacique salió tras ellos dispuesto a darles un severo castigo. La Pachamama respondió al pedido de auxilio de la joven y abrió el pliegue de su manto recogiéndolos en él: el joven se convirtió en "cardón" y ella en la flor que lo acompaña.

Por su parte, existe una narrativa asociada a la religión católica (de Mollo, 1993) sobre los "antigales" que da cuenta del origen de los "cardones" y explica algunos aspectos de la religiosidad local. Dicho relato cuenta que Dios castigó a los pecadores con un gran diluvio, momento en el cual la gente se enterraba buscando refugio bajo tierra, mientras que aquellos que se mantuvieron afuera con sus hijos se transformaron en "cardones". El tallo es la madre y cada brazo que tiene una "guagua". 
Por ello, donde hay muchos "cardones" se sabe que el sitio era un pueblo y donde hay pocos, un caserío.

En todas las narrativas descriptas, tanto las registradas a campo como las halladas en fuentes secundarias, se observa un vínculo directo de los "cardones" con la Pachamama (o Dios, al convertir la deidad al del catolicismo), que en los relatos interviene como protectora/ castigadora y es canalizadora y responsable de la transformación de las personas en "cardones". Los ritos, prácticas y concepciones tradicionales asociados a la Pachamama están enérgicamente vigentes en la zona y entre los entrevistados (Mariscotti, 1966), y habiéndose originado los "cardones" gracias a ella, quizás los vínculos tan fuertes del humano con el "cardón" en parte se deben a los intensos lazos con la Pachamama. En esta línea, los resultados indican la presencia de varios rasgos de animacidad en los "cardones", y los vínculos de las personas están en concordancia con ello. El término y concepto 'animacidad' se emplea aquí en la misma forma que Montani (2017: 54) y Suárez \& Montani (2010) lo hacen, simplemente para hacer referencia al carácter animado de una entidad definido por varios criterios, en particular la capacidad de tener cierto grado de intención, conciencia y voluntad. Algunos rasgos de animacidad encontrados son: a) en los relatos míticos los cardones son el resultado de la metamorfosis de los seres humanos; b) tienen voluntad, i.e. deciden estar en un sitio (crecer o quedarse luego del transplante), deciden pinchar a alguien, son agresivos, "contreros", porfiados, pícaros, traviesos, se muestran serios; c) varias partes de la planta son análogas a las partes humanas: pie, corazón, brazos; d) la morfología externa de los "cardones" es análoga a la de las personas: cualquiera que observa los "cardones" desde lejos, no deja de asemejarlos a personas o incluso confundirlos con ellas, y los niños se camuflan con él durante sus juegos. En los últimos dos puntos, la analogía de partes del cuerpo humano y de la planta (o de los cuerpos enteros) se basa en semejanzas funcionales, morfológicas y/o posicionales, pero además se combina con explicaciones míticas y simbolismos que en algunos casos dotan de animacidad a tal o cual parte.
Por otro lado, un rol relevante de los "cardones" para la gente, y que también dice mucho de las concepciones y los vínculos que tiene la gente con ellos, es el de guardianes de la quebrada. Este rol se explica, al menos en parte, por algunas versiones de las narrativas recopiladas, según la cual los "cardones" tienen su origen en antiguos guerreros. Los "cardonales" serían entonces los sitios donde antaño había agrupaciones de soldados, mientras que los ejemplares aislados serían soldados que se encontraban dispersos o individuos que al intentar huir de la maldición ocuparon sitios más lejanos. En este sentido, la mayor presencia de "cardones" en "antigales" que en otros sitios de la quebrada, se explica por su rol de guardianes y protectores del sitio, pero además porque " $a l$ ser un lugar de los ancestros, se dan bien". La abundancia de "cardones" en estos sitios es considerada lógica por los lugareños, en tanto es allí donde los "cardones" ofician de guardianes, protegiendo y resguardando el lugar, pero también es lógica porque es allí donde vivieron hace mucho tiempo los antepasados de los mitos en los que los hombres se convirtieron en "cardones". Aquí vale destacar que en varias versiones de los mitos se menciona que el "cardón" resulta de la fusión de un hombre y una mujer. Esto explica que los "cardones" posean atributos tanto de protección (espinas, robustez), asociados a lo masculino, como de gran belleza (flores), asociado a lo femenino, lo cual se desprende de los relatos (en forma explícita en varios casos). Además, también explica que las ramas pequeñas sean "guaguas", a las que el "cardón" abraza y sostiene hasta que crecen. Algunas hipótesis académicas sugieren que la abundancia de "cardones" en "antigales" se debe a que son sitios de asentamiento en el pasado, en donde el consumo de frutos de "cardón" por los pobladores habría sido una fuente de semillas constante que con el tiempo fueron germinando (Oliszewski, 2004; Halloy, 2008; Petrucci \& Tarragó, 2015). Además, es probable que el manejo del entorno que las sociedades han hecho en el pasado siga condicionando en laactualidad el establecimiento de los "cardones" en determinados sitios. Algunos autores han encontrado que especies del género Trichocereus suelen abundar en terrenos o ambientes fuertemente intervenidos, 
considerándola en ciertos casos una planta ruderal (Rodríguez-Arévalo et al., 2006; Halloy, 2008; Petrucci et al., 2018). Todo esto sugiere un posible origen antrópico de los "cardonales", o al menos un efecto antrópico significativo en el establecimiento de los mismos. En tiempos más recientes, el carácter sagrado de los sitios y la importancia de los "cardones" como guardianes allí, les ha dado cierta protección a los "cardones" frente a su corte y aprovechamiento, lo cual a su vez favorece su abundancia y su perduración.

Los resultados en su conjunto también se constituyen en una muestra clara de la profundidad y detalle en los conocimientos que poseen los pobladores locales sobre el "cardón", su hábitat y otros seres y elementos naturales de la zona. Esto no llama la atención, teniendo en cuenta que son ellos quienes habitan el territorio desde siempre. Los entrevistados conocen los detalles de la morfología del "cardón” y nombran las distintas partes (Tabla 1). Es interesante notar que las partes nombradas y descriptas son aquellas que la gente utiliza y observa habitualmente, aquellas a las que presta atención dado que les sirve para identificar, conocer y utilizar al "cardón". Algunas personas incluso han explicitado que si bien en la escuela les habían enseñado los nombres de otras partes ( $p$. ej. partes de la flor, como estambres o gineceo), ya no los recuerdan, dado que no los necesitan en lo cotidiano. Además, términos como "guaguas", aplicado a las ramas pequeñas, están en relación directa con las concepciones, historia y costumbres locales tradicionales (deriva del quichua "wawa": niño de pecho, niño pequeño; Barbarich, 2017: 308). Los nombres vernáculos del "cardón" también incluyen o se asocian con caracteres destacados de los "cardones". Por un lado, la voz "cardón" está muy difundida en distintos lugares del continente para denominar a otros cactus columnares: p. ej. Pachycereus pecten-aboriginum (Engelm. ex S.Watson) Britton \& Rose, "cardón Borbón", Bolivia (VegaVillasante et al., 1996); Stenocereus griseus (Haw.) Buxb., "cardón de dato", Venezuela (Terán et al., 2008) y Cereus repandus (L.) Mill., “cardón”, Venezuela (Nassar \& Emaldi, 2008); Stetsonia coryne (Salm-Dyck) Britton \& Rose, "cardón”, Gran Chaco (Arenas \& Scarpa, 1999); Cereus aethiops Haw. y Trichocereus candicans
(K. Schum.) Britton \& Rose, "cardón”, La Pampa, Argentina (Prina et al., 2015). "Cardón" provendría de la palabra cardo, del latín cardus, que a su vez deriva del griego "káktos" que en español derivó en cactus, más el epíteto -ón que, en español, funciona como aumentativo (Foury, 1997; RAE 2014). Es posible entonces que el nombre "cardón" se aplique a plantas espinosas de mayor tamaño (¿o más espinosas?) que el cardo (Cynara cardunculus L., Asteraceae), al cual originalmente se aplicaron dichos nombres, y en ocasiones con alguna otra similitud aparte de las espinas, ya sea morfológica o de otros atributos. Esta hipótesis se ve reforzada al observar que el nombre "cardón" se usa en distintas partes del mundo para aludir a otras plantas que pinchan que no son cactus, como el "cardón canario" (Euphorbia canariensis L., Euphorbiaceae) o el "agave" (Agave americana L., Agavaceae) (Guillot-Ortíz et al., 2009; Pardo de Santayana, 2014). Por otro lado, el nombre "pasacana", que refiere primariamente al fruto pero también se emplea para referirse al "cardón", parecería provenir del español pasa (arrugado) y cana (cana blanca) (Barbarich, 2017: 458) y hace alusión a las vellosidades típicas del fruto (Fig. 3D). El hecho de que se destaquen los pelos del fruto en el nombre vernáculo no es una situación inusual: a otros cactus presentes en la zona de estudio los lugareños les dan nombres por su morfología y la abundante presencia de pelos, tal es el caso Cleistocactus smaragdiflorus (F.A.C. Weber) Britton \& Rose, llamado comúnmente "cola de zorro" u Oreocereus celsianus (Lem. ex Salm-Dyck) Riccob. y O. trollii, llamados "viejo", "cabeza de viejo", "vicuñita, "ovejita".

Los conocimientos detallados que poseen los entrevistados sobre el "cardón" también queda en evidencia al reconocer especies: distinguen las distintas especies de Trichocereus con precisión, e incluso reconocen "variedades" diferentes en base a caracteres morfológicos y/u organolépticos específicos (p.ej. color de la flor, características de las espinas, porte). Estas variantes podrían corresponder a las subespecies propuestas de acuerdo a su distribución E-O (Kiesling et al., 2011). Conocen también la fenología de cada especie al detalle, así como las especies de aves y otros animales con las que los "cardones" mantienen alguna relación. Además, la distribución espacial de los "cardones" en 
la quebrada es explicada localmente por un conjunto de factores culturales (incluyendo lo antedicho sobre las explicaciones míticas y su rol como protectores de sitios arqueológicos) y ecológicos, que demuestran simultáneamente la histórica relación de la gente con los "cardones" e implican poseer conocimientos detallados y holísticos del funcionamiento del ecosistema. La larga tradición de convivencia con la especie es además un elemento clave a la hora de evaluar los factores que pueden explicar la abundancia de "cardonales" en sitios con intervención antrópica, como se mencionó con antelación. La utilidad del "cardón" y sus partes para diversos fines específicos (Tabla 1) también es una clara muestra de la larga relación de la gente con estos cactus, que ha permitido que la gente posea saberes detallados sobre estos aspectos. Al respecto, se destaca el papel del "cardón" como recurso maderero. El uso de la madera data de tiempos prehispánicos, según lo demuestra el hallazgo de piezas arqueológicas de madera de "cardón" (Calo et al., 2006; Petrucci \& Tarragó, 2015). En la actualidad toma gran relevancia no sólo porque permite construir viviendas, mobiliario y ornamentos, sino porque esta aplicación es la única entre las registradas que hoy trasciende el ámbito doméstico. Así, la madera como materia prima, objetos de madera y mano de obra relacionada a la construcción con "cardón" permiten a la gente, en los tiempos que corren, obtener ingresos monetarios para la familia. Cabe destacar que desde 2006 la regulación provincial del recurso prohíbe su uso para construcción y mobiliario (Decreto Provincial $\left.N^{\circ} 4805 / 06\right)$, lo cual ha generado que los pocos productos que se utilizan y elaboran estén muy restringidos y que la mayor parte de la madera se destine a elementos artesanales, cuya venta sí está permitida. La madera también sirve como leña de emergencia, ya que no es de las leñas de mejor calidad, al igual que lo que ocurre en otras regiones y culturas con otros cactus de porte columnar, como Stetsonia coryne en el Gran Chaco, o Pachycereus weberi (J.M. Coult.) Backeb. en México (Arenas \& Scarpa, 1999; Casas, 2002; Suárez, 2014: 242-243). Por otro lado, el empleo del "cardón" como reservorio de agua es también de gran importancia local. Es muy común que la gente conozca y valore mucho a las plantas hidrorreservantes en regiones áridas y semiáridas, donde el agua es uno de los bienes más preciados $\mathrm{y}$, en esta línea, el mucílago de cactáceas es conocido y empleado en distintas partes con este fin (cf. Arenas, 2003; Schulze Rojas \& Linares, 2004; Reveles-Hernández et al., 2010; Suárez 2014: 232, 235). Además de los usos ya mencionados, se registraron otra serie de aplicaciones vinculadas con la alimentación, la medicina, la veterinaria, la tecnología, los juegos infantiles y la decoración, que muestran la presencia constante del "cardón" en los diversos ámbitos de la vida cotidiana de la gente (Tabla 1).

Los vastos y pormenorizados saberes de los pobladores sobre el "cardón" y los vínculos particulares que la gente mantiene con ellos son motivo más que suficiente para que algunos los datos que surgieron de la investigación relativos al estado sanitario de estas plantas y del ambiente en general de la quebrada sean considerados seriamente y despierten un alerta urgente. Según los entrevistados, los "cardones" sirven como indicador ambiental y, dado que su estado sanitario empeora cada día, se entiende que el ecosistema en general está en mal estado. Esto último es un resultado novedoso y a tener en cuenta, ya que en el ámbito académico, si bien hay trabajos que refieren a una situación ambiental más o menos grave (García Codrón \& Silió Cervera, 2001; Castro, 2015), no hay estudios sistemáticos ni enfocados en la temática. A juzgar por los dichos de la gente sobre la vertiginosidad en el aumento de las muertes de "cardones" por pudrición (de causa desconocida) y a la cada vez mayor infestación de los mismos por Cactoblastis bucyrus debido a la merma de aves que las regulan, las acciones tendientes a comprender y mejorar la situación ambiental deben comenzar a implementarse en lo inmediato. Más aún, los entrevistados sostienen que la tasa de germinación de "cardones" es sumamente baja. De Viana (1999) reportó la baja capacidad de repoblación de los "cardones", atribuyéndola principalmente a la baja germinabilidad, con germinación fotosensible. El ganado foráneo, introducido en la región hace siglos, aún cuando es un elemento de dispersión de semillas importante, también produce daño a los "cardones". Si bien la gente manifiesta que 
éste no sería significativo dado que los animales consumen tejidos verdes del "cardón" solo en épocas de escasez de agua o alimento, estudios realizados sobre este tema indican lo contrario (Villalobos et al., 2007; Peco et al., 2011). A ello se suma la alta demanda local y regional de madera de "cardón" para la construcción o adornos de emprendimientos hoteleros y turísticos de envergadura en la zona, que ha aumentado con el tiempo (cfr. http://www. ellibertario.com/2009/10/05/en-pocos-anoshubo-una-notable-reduccion-de-cardones-enla-quebrada/ y Decreto Provincial 4805/2016, Jujuy). Mientras las prácticas tradicionales de uso de la madera parecieran estar reguladas por pautas y conocimientos ancestrales sobre la cantidad y selección de "cardones" a cortar para que la población se mantenga, los emprendimientos hoteleros y gastronómicos de la zona han generado un uso desmedido de madera de "cardón", aún en contra de la regulación provincial vigente que prohíbe el corte de "cardones". Considerando todo lo antedicho, hay un indicio fuerte de que los "cardones" de la Quebrada de Humahuaca están o pronto pueden estar en peligro y junto con ellos, los vínculos, saberes y prácticas que los pobladores kollas mantienen con estos íconos de la región.

\section{Conclusiones}

El "cardón", Trichocereus atacamensis, es una, sino 'la' especie botánica más emblemática de la Quebrada de Humahuaca para los pobladores locales. Los "cardones" le dan identidad a la región y a la vez su identidad está relacionada con la quebrada. El pueblo kolla lleva siglos en el territorio, lo cual explica los estrechos lazos, las particularidades del vínculo y los conocimientos detallados que poseen sobre el "cardón" y su hábitat. Más allá de los cambios socioculturales, políticos y ambientales acontecidos con el correr del tiempo, y pese a la creciente urbanización, los resultados indican que los relatos, prácticas y saberes asociados al "cardón" se mantienen. El conjunto de información reunida en esta investigación contribuye a conocer la etnobotánica de una especie de gran significancia local, que hasta hoy no había sido abordada en forma integral. Sin embargo, los resultados también sugieren que el estado sanitario de los "cardones" y de la zona de estudio es preocupante. Urge entonces encarar estudios multidisciplinarios que permitan conocer mejor la situación ambiental de la región, para poder pensar estrategias y acciones concretas para revertirla. De lo contrario, los "cardones" -guardianes fieles de la quebrada- y los conocimientos y prácticas asociadas de su gente, irán desvaneciéndose para permanecer sólo en los relatos, recuerdos y añoranzas de los que alguna vez los vieron en su esplendor.

\section{Agradecimientos}

A nuestros colaboradores en territorio, auténticos poseedores de todos los saberes que en el presente trabajo recopilamos, sistematizamos y analizamos, quienes generosamente han compartido información, actividades cotidianas y en definitiva parte de su vida con nosotros. Entre ellos, especialmente a Doña Fina y el Zorro Paredes in memorian. A Juan A. Barbarich, Marcela Ramos, Beatriz Galati, Sonia Rosenfeld, Rodrigo Montani y Américo Vilte, por sus aportes y comentarios al manuscrito. Las autoras también agradecen a los revisores anónimos que ayudaron a mejorar el manuscrito. El presente proyecto fue financiado parcialmente por el CONICET, la ANPCYT (PICT-2013-1633, PICT-2013-2190) y la UBA (UBACYT 20020150200191BA).

\section{Bibliografía}

ARENAS, P. 2003. Etnografía y alimentación entre los Toba-Nachilamole\#ek y Wichí-Lhuku'tas del Chaco Central (Argentina). Ed. Pastor Arenas, Buenos Aires. 562 pp.

ARENAS, P. \& G. J. MARTÍNEZ. 2012. Estudio etnobotánico en regiones áridas y semiáridas de Argentina y zonas limítrofes. Experiencias y reflexiones metodológicas de un grupo de investigación. En ARENAS, P. (ed.), Etnobotánica en zonas áridas y semiáridas del Cono Sur de Sudamérica, pp. 11-43. Cefybo-conicet, Buenos Aires.

ARENAS, P. \& G. F. SCARPA. 1999. Ethnobotany of Stetsonia coryne (Cactaceae), the "cardón" of the Gran Chaco. Haseltonia 6: 42-51. 
BARBARICH, J. A. 2017. Trancabalanca: Diccionario del habla rural de Jujuy. Colección Producción Científica, Editorial de la Universidad Nacional de Jujuy. 712 pp.

BENEDETTI, A. 2012. Quebrada de Humahuaca: ¿hoya, unidad fisiográfica, región geográfica, ambiente o lugar? Estudio bibliográfico sobre la toponimia y el pensamiento geográfico regional argentino (siglos XIX y XX). Registros. Revista de investigación histórica 7: 111-138.

BERGESIO, L. \& J. MONTIAL. 2008. Patrimonialización de la Quebrada de Humahuaca: identidad, turismo y después... Encuentro pre-alas 2008-Preparatorio del XXVII Congreso ALAS Buenos Aires 2009. UNNE, Posadas.

CABRERA, A. L. 1971. Fitogeografía de la república Argentina. Bol. Soc. Argent. Bot. 14: 1-42.

CALO, C. M., S. M. RIVERA \& M. C. SCATTOLIN. 2006. Los recursos combustibles arqueológicos en Loma Alta (Catamarca, Argentina). An. Arqueol. Etnol. 61-62: 165-175.

CAPPARELLI, A. \& R. RAFFINO. 1997. La etnobotánica de El Shincal (Catamarca) y su importancia para la arqueología I: Recursos combustibles y madereros. Parodiana 10: 181-188.

CÁRDENAS, M. 1951. Notes on Eastern Bolivian Cactaceae. Natl. Cact. Succ. J 49: 8-9.

CARRIZO, J. A. 1989. Cancionero popular de Jujuy. Tomo I. Ediunju, Jujuy. 477 pg.

CASAS, A. 2002. Uso y manejo de cactáceas columnares mesoamericanas. CONABIO. Biodiversitas 40: 18-23.

CASTRO, H. 2015. Crónicas de desastres, tramas del riesgo: Contribuciones para una historia ambiental de la Quebrada de Humahuaca. Poblac. Soc. 22: 128-130.

CRUZ, G. M. 2008. El conocimiento tradicional sobre los recursos vegetales como factor de desarrollo local en Juella, Dpto. Tilcara, Provincia de Jujuy- Argentina. Tesis de Magister. Facultad de Ciencias Agrarias, Universidad Nacional de Jujuy.

DE GRANDA, G. 1993. Quechua y español en el noroeste argentino. Una precisión y dos interrogantes. Lexis 17: 259-274.

DE MOLLO, P. M. 1993. Leyendas de nuestra tierra, Volumen 17. Ediciones Del Sol. Buenos Aires, Argentina. $120 \mathrm{pp}$.

DE VIANA, M. L. 1999. Seed production and seed bank of Trichocereus pasacana (Cactaceae) in Northwestern Argentina. Trop. Ecol. 40: 79-84.

DIGUET, L., D. BOIS \& A. GUILLAUMIN. 1928. Cactacée sutiles du Mexique. Au siège de la Société, Paris, $551 \mathrm{pp}$.

FELDMAN GRACIA, L. 2011. Coca y wachuma: sus prácticas y significados en la cultura andina y en Lima. Tesis doctoral, Univ. Nac. Mayor de San Marcos, Lima, Perú.
FERNÁNDEZ DISTEL, A. 1984. Contemporary and archaeological evidence of llipta elaboration from cactus Trichocereus pasacana in Northwest Argentina. En BROWMAN, D., R. BURGER \& A. RIVERA (eds.), Social and Economic Organization in the Prehispanic Andes, pp. 193203. BAR International Series 194, Oxford.

FOURY, C. 1997. Propos sur l'origine de l'artichaut et $\mathrm{du}$ cardon. Journal d'agriculture traditionnelle et de botanique appliquée 39 (1): 133-147.

GARCÍA CODRÓN, J. C. \& F. SILIÓ CERVERA, F. 2001. Riesgos naturales en los Andes: cambio ambiental, percepción y sostenibilidad. Bol. A.G.E. 30: 69-84.

GARCÍA MORITÁN, M. \& M. B. CRUZ. 2012. Comunidades originarias y grupos étnicos de la provincia de Jujuy. Poblac. Soc. 19: 155-173.

GUILlOT-ORTÍZ, D. G., P. VAN DER MEER, E. LAGUNA LUMBRERAS \& J. A. ROSSELLÓ PICORNELL. 2009. El género Agave L. en la flora alóctona valenciana. Monografías de la revista Bouteloua 3. José Luis Benito Alonso, Jaca (Huesca). 94 pp.

HALLOY, S. 2008. Crecimiento exponencial y supervivencia del cardón (Echinopsis atacamensis subsp. pasacana) en su límite altitudinal (Tucumán, Argentina). Ecol. Boliv. 43: 6-15.

HEYNE, C. 1992. Identifying prehispanic wood from archaeological contexts in Andean Argentina. Tesis de Grado, Facultad de Arqueología, Univ. Minnesota, EE.UU.

HILGERT, N. I. 2000. Especies vegetales empleadas en la insalivación de hojas de "coca" (Erythroxylum coca var. coca, Erythroxylaceae). Darwiniana 38: 241-252.

HILGERT, N. I. \& R. KIESLING. 2002. The utilization of cacti in the upper Río Bermejo basin, Salta, Argentina. Haseltonia 9: 1-10.

INDEC (Instituto Nacional de Estadísticas y Censos). 2010. Censo Nacional de Población, Hogares y Viviendas 2010: Censo del Bicentenario. Pueblos originarios: región Noroeste Argentino. - 1a ed. - Ciudad Autónoma de Buenos Aires. (acceso 10.12.17) https://www.indec.gov.ar/ftp/cuadros/ poblacion/pueblos_originarios_NOA.pdf

ISE (International Society of Ethnobiology). 2006. Code of Ethics (with 2008 additions). http:// ethnobiology.net/code-of-ethics/ (acceso 24.08.17).

KARASIK, G. A. \& R. MACHACA. 2016. Kollas de Jujuy. Un pueblo, muchos pueblos. Pueblos indígenas en la Argentina cap. 6. Ministerio de Educación y Deportes de la Nación, Buenos Aires. $40 \mathrm{pp}$.

KIESLING, R. 1978. El género Trichocereus (Cactaceae) I: Las especies de la República Argentina. Darwiniana 21: 263-330. 
KIESLING, R., M. SARAVIA, L. OAKLEY, N. MURUAGA, D. METZING \& L. NOVARA. 2011. Cactaceae. Aportes Botánicos de Salta-Serie Flora 10 (7): 1-142.

LÓPEZ, L. E. 2010. Pueblos, culturas y lenguas indígenas en América Latina. Atlas sociolingüístico de pueblos indígenas en América Latina, pp. 21-99. UNICEF.

MARISCOTTI, A. M. 1966. Algunas supervivencias del culto a la Pachamama: el complejo ceremonial del 1 de Agosto en Jujuy (NO Argentino) y sus vinculaciones. Z. Ethnol. 1: 68-99.

MARTÍNEZ SARASOLA, C. 1992. Nuestros Paisanos Los Indios. Vida, historia y destino de las comunidades indígenas en la Argentina. Emecé, Buenos Aires. 816 pp.

MINHONDO, C. 2011. Propuesta didáctica: la leyenda. Ed. UNC, Córdoba. 16 pp.

MONTANI, R. 2017. El mundo de las cosas entre los wichís del Gran Chaco. Un estudio etnolingüístico. Itinerarios Editorial \& CIHA, Cochabamba. 607 pp.

NASSAR, J. M. \& U. EMALDI. 2008. Fenología reproductiva y capacidad de regeneración de dos cardones, Stenocereus griseus (Haw.) buxb. y Cereus repandus (L.) Mill. (Cactaceae). Acta Bot. 31: 495528.

OLISZEWSKI, N. 2004. Estado actual de las investigaciones arqueobotánicas en sociedades agroalfareras del área valliserrana del noroeste argentino (0 - 600 d.C.). Relac. Soc. Argent. Antropol. 29: 211-227.

ORTEGA-BAES, P. \& H. GODÍNEZ-ALVAREZ. 2006. Global diversity and conservation priorities in the Cactaceae. Biodivers. Conserv. 15: 817-827.

PARDO DE SANTAYANA, M. 2014. Etnobotánica e inventario español de conocimientos tradicionales. Conservación vegetal 18. Disponible en: https:// repositorio.uam.es/bitstream/handle/10486/665993/ CV_18_1.pdf?sequence $=1 \&$ is Allowed $=y$ (acceso 10.03.2018)

PECO, B., C. E. BORGHI, J. E. MALO, P. ACEBES, M. ALMIRÓN \& C. M. CAMPOS. 2011. Effects of bark damage by feral herbivores on columnar cactus Echinopsis (= Trichocereus) terscheckii reproductive output. J. Arid. Environ. 75: 981-985.

PETRUCCI, N. \& M. TARRAGÓ. 2015. Restos Arqueobotánicos del Sitio Rincón Chico 1. Una aproximación a los posibles escenarios de procesamiento, uso y consumo. Comechingonia 19: 67-86.

PETRUCCI, N., V. S. LEMA, M. L. POCHETTINO, V. PALAMARCZUK, R. SPANO \& M. TARRAGÓ. 2018. From weeds to wheat: a diachronic approach to ancient biocultural diversity in the Santa María valley, northwest Argentina. Veg. Hist. Archaeobot. 27: 229-239.

PINTAR, E. 2004. Cueva Salamanca 1: ocupaciones altitermales en la Puna sur (Catamarca). Relac. Soc. Argent. Antropol. 29: 357-366.
PRINA, A, W. MUIÑO, M. GONZÁLEZ, A. TAMAME, L. BEINTICINCO, D. MARIANI \& V. SARAVIA. 2015. Guía de Plantas del Parque Nacional Lihué Calel. Editorial Vision 7, Santa Rosa. 208 pp.

RAE (Real Academia Española). 2014. Diccionario de la lengua española ( $23^{\circ}$ edición). Disponible en: http:// www.rae.es/ (acceso 15.03.18).

REBORATTI, C. 1998. El Alto Bermejo. Realidades y conflictos. La Colmena, Buenos Aires. 216 pp.

REVELES-HERNÁNDEZ, M., M. A. FLORES-ORTÍZ, F. BLANCO-MACÍAS \& R. D. VALDÉZ-CEPEDA. 2010. El manejo del nopal forrajero en la producción del ganado bovino. VIII Simposio-Taller Nacional y 1er Internacional "Producción y Aprovechamiento del Nopal”. RESPYN Edición Especial 5: 130-144.

RODRÍGUEZ-ARÉVALO, I., A. CASAS, R. LIRA \& J. CAMPOS. 2006. Uso, manejo y procesos de domesticación de Pachycereus hollianus (F.A.C.Weber) Buxb. (Cactaceae), en el valle de Tehuacán-Cuicatlán, México. Rev. Intercie. 31: 677-685.

ROS, C. C. \& S. SCHNEIDER. 2008. Estrategias campesinas de reproducción social. El caso de las Tierras Altas Jujeñas, Argentina. Rev. Int. Sociol. 66: 163-185.

SÁNCHEZ MEJORADA, H. 1982. Algunos usos prehispánicos de las cactáceas entre los indígenas de México. Gobierno del Estado de México. Secretaría de Desarrollo Agropecuario. Toluca, México 48 pp.

SCHULZE ROJAS, J. P. \& J. LINARES. 2004. Elaboración de una guía ilustrada de Cactáceas en Honduras (No. T1945). Escuela Agrícola Panamericana El Zamorano, Honduras. 80 pp.

SLOTKIN, J. S. 1956. The Peyote religion: a study in Indian-White relations. IL: Free Press, Glencoe. 195 pp.

SOLARI, E. 1907. Geografía de la Provincia de Jujuy. Peuser, Buenos Aires. 64 pp.

STEWART, O. C. 1987. Peyote religion: a history. Univ. of Oklahoma Press, Norman.

SUÁREZ, M. E. 2014. Etnobotánica wichí del bosque xerófito en el Chaco Semiárido salteño. Autores de Argentina, Don Torcuato. 522 pp.

SUÁREZ, M. E. \& R. M. MONTANI. 2010. Vernacular knowledge of Bromeliaceae species among the Wichí people of the Gran Chaco, Argentina. J. Ethnobiol. 30: 265-288.

TERÁN, Y., R. D' AUBETERRE \& M. P. DE CAMACARO. 2008. Caracterización física y química del fruto de cardón de dato de los municipios Torres y Jiménez, estado Lara, Venezuela. Agronomía Tropical 58: 17-20.

THE PLANT LIST. 2013. Version 1.1. http://www. theplantlist.org/ (acceso 10.03.18).

TOMASI, J. \& RIVET, C. 2011. Puna y arquitectura. Las formas locales de la construcción. CEDODAL, Buenos Aires. 180 pp.

TOWLE, M.A. 1961. The Ethnobotany of Pre-Columbian Peru. Viking Fund Publications no. 20. Aldine, Chicago. 
TRONCOSO, C. A. 2009. Patrimonio y redefinición de un lugar turístico: La Quebrada de Humahuaca, Provincia de Jujuy, Argentina. Estud. Perspect. Tur. 18: 144-160.

VEGA-VILLASANTE, F., H. NOLASCO, C. MONTAÑO, H. ROMERO-SCHMIDT \& E. VEGAVILLASANTE. 1996. Efecto de la temperatura, acidez, iluminación, salinidad, irradiación solar y humedad sobre la germinación de semillas de Pachycereus pecten-aboriginum "cardón barbón" (Cactaceae). Cact. Suc. Mex. 41: 51-61.

VILLAFUERTE, C. 1986. Leyendas de nuestra tierra. Corregidor, Buenos Aires. 219 pp.

VILLALOBOS, S., O. VARGAS \& S. MELO. 2007. Usage, managment and conservation of "yosú", Stenocereus griseus (Cactaceae), in the Upper Guajira, Colombia. Acta Biol. 12: 99-112.
VIGNALE, N. D. 1996. Plantas medicinales del área andina de la Provincia de Jujuy. An. Soc. Argent. Invest. Prod. Aromát. 14: 177 - 182.

VON ROSEN, E. 1904. Archaeological researches on the frontier of Argentina and Bolivia in 1901-1902. Annu. Rep. Smithson. Inst. 50: 573-581.

WAHYUNI, D. 2012. The Research Design Maze: Understanding Paradigms, Cases, Methods and Methodologies. JAMAR 10: 69-80.

YUDI, R. 2014. Kollas de nuevo. Etnicidades, trabajo y clasificaciones sociales en los Andes de la Argentina. Purmamarka, Jujuy,Argentina. 253 pp.

ZULOAGA, F., O. MORRONE \& M. BELGRANO. 2008. Catálogo de las plantas del Cono Sur. Base de datos de actualización permanente. Disponible en: http://www2.darwin.edu.ar/Proyectos/ FloraArgentina/fa.htm (acceso 10.03.18).

Original recibido el 16 de abril de 2018; aceptado el 20 de mayo de 2018. 